\title{
Considerações iniciais sobre a segurança hídrica do Brasil
}

\section{First considerations on water security in Brazil}

\section{SIDNEI LOPES RIBEIRO}

\section{INTRODUÇÃO}

A água é recurso escasso e o mais desigualmente distribuído, pois só 0,3\% é consumível, nove países têm mais de $60 \%$ e outros nove, no Oriente Médio, têm a menor disponibilidade. Mesmo com a maior disponibilidade mundial, o recurso hídrico distribui-se desigualmente: no Brasil há $68 \%$ no Norte, mas só 3\% no Nordeste; das águas superficiais, no mundo a agricultura consome $69 \%$, a indústria $23 \%$, as residências $8 \%$ e o Brasil utiliza $61 \%$ na agricultura, $21 \%$ em domicílios e $18 \%$ em indústrias; e das águas subterrâneas, nosso país usa $38 \%$ na agricultura, $37 \%$ na indústria e $25 \%$ em domicílios (Bassoi; Guazelli 2004, 55; Becker 2004, 155).

As recentes secas da Amazônia, em 2005 e 2010, e no Sudeste, em 2014, além da tragédia do rio Doce (2015) indicam que a gestão dos recursos hídricos precisa de ajustes para minimizar efeitos de eventos extremos e evitar o comprometimento do desenvolvimento do país. Portanto, consideramos o recurso hídrico um fundamento da segurança e da defesa do país, segundo o princípio geopolítico de que "qualquer fortaleza deve ser capaz de resistir a um cerco prolongado contando exclusivamente com os recursos disponíveis em seu interior" (Gómez 2006, 177). Assim, a política de segurança do Brasil deve considerar a segurança ambiental (seguranças hídrica, alimentar, energética, tecnológica, etc.) para garantir o desenvolvimento e a defesa da nação.

Nossa tese sobre segurança ambiental possui dois fundamentos: o primeiro, e específico para este artigo, é que o país deve executar uma gestão correta do recurso hídrico, garantindo a segurança hídrica como condição essencial a uma economia sustentável, à defesa contra ameaças externas e, minimizando os efeitos das crises hídricas futuras, para que não atin-

Sidnei Lopes Ribeiro - Secretaria da Educação do Estado de São Paulo. 
jam a economia e o prestígio internacional do país; o segundo fundamento engloba todos os aspectos da segurança, inclusive a ambiental: é a Geopolítica do Meio Ambiente, entendendo-se meio ambiente como o fundamento da sobrevivência e do desenvolvimento (humano, científico, tecnológico, etc.) dos povos, só possível em presença da paz e da prosperidade nacional e internacional.

Portanto, este artigo sobre segurança ambiental faz revisão e análises bibliográfica e documental ao tratar de ações efetivas da segurança hídrica. $\mathrm{Na}$ segunda seção propomos a ampliação do conceito de segurança, de Marques e Medeiros Filho (2014), nos eixos vertical e horizontal. Na terceira seção tratamos do eixo vertical, o geográfico, de nível nacional e comentamos documentos oficiais sobre segurança hídrica, as principais técnicas para poupar água, apresentamos um quadro síntese da situação por região do país e debatemos o assunto. Na quarta seção tratamos do eixo horizontal, da Geopolítica do meio ambiente, no nível internacional, ao comentar a cooperação internacional do Brasil com os Estados sul-americanos e de todo o mundo.

\section{SEGURANÇA HÍDRICA, AMBIENTAL E GEOPOLIITICA DO MEIO AMBIENTE}

A resposta à ideia central do texto, sobre como executar uma gestão eficiente do recurso hídrico que garanta a segurança hídrica, é muito complexa e este artigo objetiva apenas a iniciar o debate para respondê-la, pois a tarefa envolve a interligação de todos os componentes da segurança (Figura 1). Portanto, seguiu-se a definição da Parceria Mundial da Água para segurança hídrica: “[ ...] do nível doméstico ao global, significa que todos têm acesso à água potável em quantidade suficiente a um custo acessível para ter uma vida asseada, saudável e produtiva, garantindo a proteção e melhoria do ambiente natural” (GWP 2000, 12). Ela considera as escalas geográficas, os direitos universais à água e à proteção ao meio ambiente, além da melhoria do nível de vida e a realização do desenvolvimento sustentável, novo direito humano, presente no artigo 225 da Constituição Federal de 1988 (Milaré 1998, 54-67). Para o Governo Federal, segurança hídrica é a garantia de oferta de água ao povo e às atividades produtivas em situações de seca, estiagem ou desequilíbrio entre oferta e demanda do recurso, [com] enfrentamento às cheias e gestão necessária para a redução dos riscos associados a eventos críticos (Brasil 2014). 


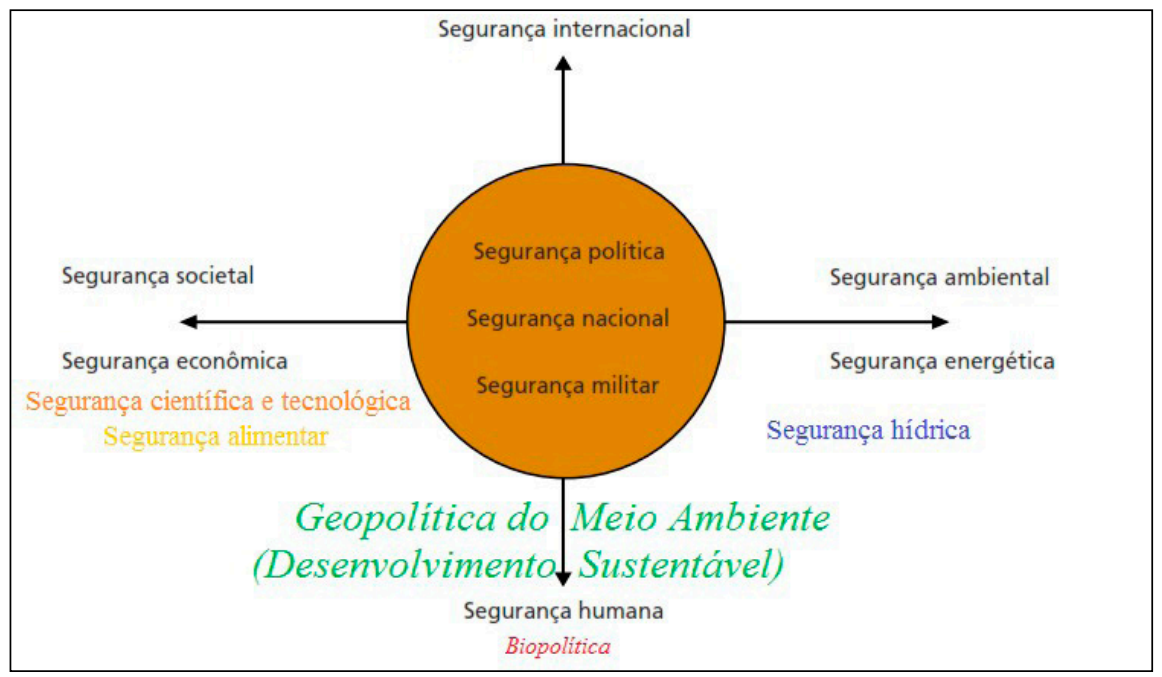

Figura 1 - Ampliação do conceito de segurança.

Fonte: Marques e Medeiros Filho (2014, 46). Textos em cores são inserções deste autor.

Como um dos instrumentos da Biopolítica (Foucault 2005, 292), o controle dos recursos hídricos dá grande poder sobre a vida, integra a segurança humana (Figura 1) e só é possível quando há segurança. Marques e Medeiros Filho ampliam o conceito de segurança (Figura 1) dividindo-o em dois eixos: o vertical, da segurança nos níveis de análise individual (humana), estatal (nacional) e transnacional (internacional); e o horizontal, que se ampliou para áreas como ambiental, social e econômica após o fim da Guerra Fria, quando deixou de ser um monopólio político-militar dos Estados (Marques e Medeiros Filho, 2014: 46).

Para nós, o eixo vertical é a escala geográfica da segurança, que começa na microescala individual (biopolítica) e termina na escala internacional; mas, na escala internacional nenhum Estado pode agir além das fronteiras porque cada um é soberano em seu território, por princípio básico do Direito Internacional. Portanto, para proteger seu ambiente, quando um Estado atua na escala geográfica internacional ele exerce Geopolítica e Direito do Meio Ambiente junto à comunidade de nações, pelo princípio da cooperação e interdependência entre os povos inserido no art. $4^{\circ}$, IX da Constituição Federal (Milaré 1998, 67).

Assim, batizamos o eixo horizontal de Geopolítica do Meio Ambiente porque, de acordo com a Figura 1, a segurança compõe-se de segurança ambiental, hídrica, alimentar, biodiversidade, serviços ambientais etc., bases do 
desenvolvimento. Mas, se algum aspecto horizontal da segurança estiver comprometido, em qualquer escala, a segurança do país estará em risco. Segundo Balmford et al. (2002), serviços ambientais como a estabilização do clima, a purificação da água, a proteção ao solo de um ambiente natural tem uma taxa de retorno de, ao menos, 1:100, ou seja, para cada $\$ 1,00$ investido na conservação do ambiente, seu retorno é, no mínimo, de \$100,00 em benefícios à humanidade.

Portanto, para nós, e com base em Kjellén Apud Vesentini (1987), Andrade (1989), Becker (1990), Ratzel (1990), Magnoli (1994), Odum (2001), Martins e Pianovski (2013) e Marshall (2014), Geopolítica é a ação do Estado, associado a outros atores nacionais e internacionais como movimentos sociais e ONGs, que manifesta seu poder político, econômico, militar ou outro a seus próprios povo e território e/ou aos de outros Estados para consolidar, manter e/ou ampliar a sua influência internacional. E, também para nós, Geopolítica do Meio Ambiente é a gestão responsável do meio ambiente do território do país, em respeito à constituição federal e em cooperação com a comunidade das nações, visando ao desenvolvimento sustentável conjunto.

Como os ambientes naturais são compartilhados pelos Estados Nacionais, os Tratados Internacionais, em tese, seriam uma forma pacífica de cooperação entre Estados para satisfazer interesses geopolíticos externos comuns. Um exemplo de organização multilateral de cooperação entre nações, para o desenvolvimento sustentável conjunto, é o Tratado de Cooperação Amazônica (TCA), de 1978 (Brasil 1980). Ele originou a Organização do Tratado de Cooperação Amazônica (OTCA) em 1998, com sede em Brasília (Brasil 2016), e a Agenda Estratégica de Cooperação Amazônica (AECA), em 2010 (OTCA 2011). E, para iniciar a resposta à questão sobre como fazer a gestão eficiente do recurso hídrico e garantir a segurança hídrica do país, enfocamos os eixos vertical e horizontal da segurança, nas escalas geográficas nacional e internacional.

\section{EIXO VERTICAL: A SEGURANÇA HÍDRICA NACIONAL}

Ampliamos o conceito de segurança de Marques e Medeiros Filho (2014), ao tratarmos da segurança hídrica na escala geográfica nacional.

\section{Medidas oficiais para a segurança hídrica}

A década de 1980 foi decisiva para a legislação de meio ambiente, pois o Estado mudou o discurso e iniciou densa legislação de meio ambiente com a Lei $n^{\circ}$ 6938/1981, a Política Nacional de Meio Ambiente, marco na área. Em 1988 o artigo 225 da Constituição Federal consolidou o novo pa- 
radigma de proteção ao meio ambiente do País e a diplomacia do governo Sarney trouxe ao Rio de Janeiro a II Conferência das Nações Unidas sobre Meio Ambiente e Desenvolvimento, a Rio 92 (Ribeiro 2006). E a Lei $n^{\circ}$ 9433/ 1997 instituiu a Política Nacional de Recursos Hídricos, cujos alguns fundamentos são: a água é bem de domínio público e recurso natural limitado; o consumo humano é o uso prioritário; a bacia hidrográfica é a unidade territorial de ação; a gestão é descentralizada e dela participam Poder Público, usuários e comunidades (Brasil 1997).

O Atlas Brasil: abastecimento urbano de água (Atlas) e outros documentos oficiais são ações do Estado visando à segurança hídrica, que integram a segurança ambiental, aspecto da segurança do país. A Agência Nacional de Águas (ANA) publicou o Atlas, que mapeou em todos os municípios do país as carências de abastecimento de recurso hídrico e os investimentos necessários até 2015 e 2025 (e 2035 às regiões de maior população) para garantir água a todos os municípios (ANA 2010a, b). A ANA publicou o Plano Nacional de Segurança Hídrica (PNSH) para definir obras estratégicas (barragens, adutoras, canais e eixos de integração) para garantir água ao povo e à produção, reduzindo os riscos ligados a eventos críticos (Brasil 2014).

O PNSH tem dois horizontes de trabalho: i) até 2020, para identificar as demandas por água e controle de cheias em áreas vulneráveis; ii) até 2035, para integrar as políticas públicas do setor. No PNSH, o Governo Federal reconhece que gestão e serviços de recurso hídrico ainda têm disparidades e conflitos entre os níveis de governo, os setores, as regiões e as Unidades da Federação, que competem pelo mesmo recurso (Brasil 2014a, b).

A Figura 2 traz os maiores problemas do país: a escassez estrutural do Nordeste, cujas bacias do Parnaíba (I), Atlântico Nordeste (IV) e São Francisco (V) são prioritárias por fatores populacionais e ambientais (clima semiárido, rochas cristalinas e rios intermitentes); o Sudeste, da Megalópole, atendido pelas bacias do Alto Tietê e Paraíba do Sul (II), tem grande população, poluição e concorrência pelo recurso hídrico, elevando o conflito; no Sul, a bacia do poluído rio Guaíba (III) tem problemas semelhantes aos da Megalópole. Baseados no Atlas (ANA 2010a; b), elaboramos o quadro a seguir, que resume os principais problemas, considerando mananciais superficiais e subterrâneos. 

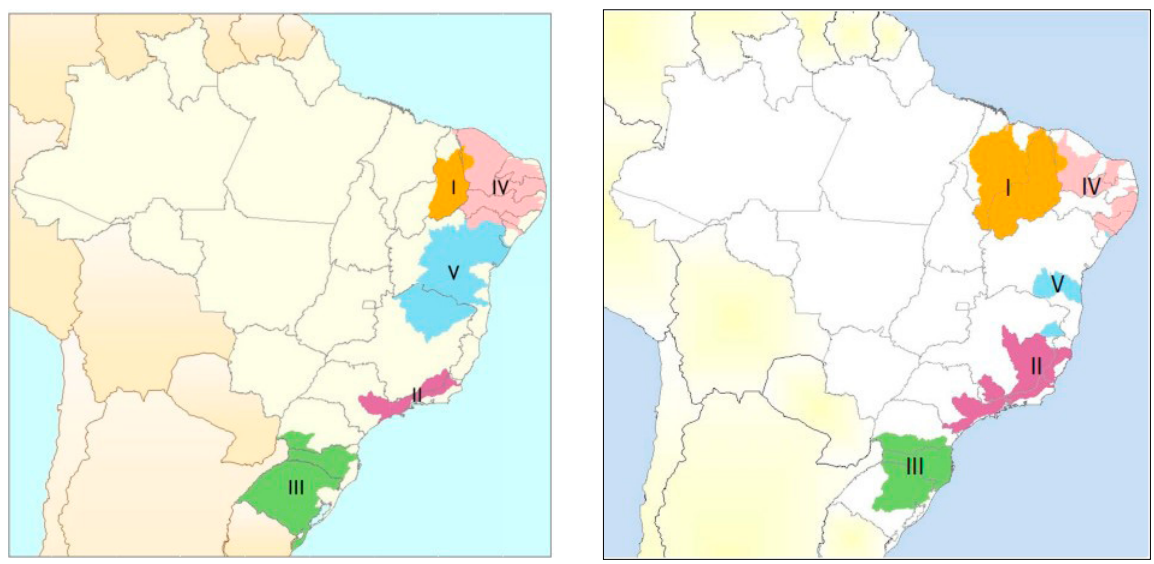

Figura 2 - Áreas prioritárias do PNSH: secas (E) e cheias (D).

Fonte: PNSH (ANA 2014, 12-13).

No Norte, os investimentos são em tratamento, abastecimento e novos mananciais, dos quais o Sistema Aquífero Grande Amazônia (SAGA), ex-Alter do Chão é promissor (Abreu; Cavalcanti; Matta 2013). No Nordeste, trabalha-se para interligar sistemas de abastecimento às aglomerações urbanas e espera-se que a conclusão do Projeto de Integração do rio São Francisco eleve a segurança hídrica e garanta água à população do semiárido (ANA 2010).

O Atlas não se referiu à dessalinização da água do mar, mas sugerimos uma usina dessalinizadora em parceria entre governo e a salineira de Areia Branca, Mossoró (RN). A eletricidade, para a operação, para entrega à população e para a ampliação da produção de sal, viria de fontes renováveis solar e eólica em cogeração, diminuindo custos e aproveitando a sazonalidade anual da extração, interrompida na época das chuvas (março a maio) para manutenção e preparo da nova safra (Norsal 2016). Uma usina de dessalinização eólica funcionaria o ano todo, ampliaria a produção e os lucros nos meses chuvosos, com a venda de eletricidade e água. 
QUADRO 1 - Principais problemas de abastecimento hídrico no país

\begin{tabular}{|c|c|c|c|}
\hline Região & $\begin{array}{c}\text { Regiões } \\
\text { hidrográficas }\end{array}$ & Aquíferos & Principais problemas \\
\hline Norte & $\begin{array}{l}\text { Amazônica, } \\
\text { Tocantins-Araguaia, } \\
\text { Atlântico Nordeste } \\
\text { Ocidental }\end{array}$ & \begin{tabular}{|l} 
SAGA, Bambuí, \\
Barreiras, Boa \\
Vista, Cabeças, \\
Formação Pirabas, \\
Iccá, Itapecuru, \\
Parecis, Tacutu \\
\end{tabular} & $\begin{array}{l}\text { Municípios sem tratamento de } \\
\text { água: } 19 \text { (AM), } 77 \text { (PA), onde } 4 \\
\text { municípios não possuem abasteci- } \\
\text { mento de água; RO: desmatamento } \\
\text { e mineração comprometem a qua- } \\
\text { lidade }\end{array}$ \\
\hline Nordeste & $\begin{array}{l}\text { Tocantins-Araguaia, } \\
\text { Atlântico Nordeste } \\
\text { Ocidental, Parnaíba, } \\
\text { Atlântico Nordeste } \\
\text { Oriental, S. } \\
\text { Francisco, Atlântico } \\
\text { Leste }\end{array}$ & \begin{tabular}{|l|} 
Barreiras, \\
Itapecuru, \\
Pernambuco- \\
Paraíba, Cabeças, \\
Poti-Piaui
\end{tabular} & $\begin{array}{l}\text { AL: cunha salina e nitratos no lito- } \\
\text { ral; Semiárido: aquíferos e bacias } \\
\text { hidrográficas de baixa disponibili- } \\
\text { dade hídrica; MA: alguns municí- } \\
\text { pios sem abastecimento público; } \\
\text { PB: região hidrográfica Atlântico } \\
\text { NE Oriental é a de menor disponi- } \\
\text { bilidade hídrica do país }\end{array}$ \\
\hline Sudeste & $\begin{array}{l}\text { S. Francisco, } \\
\text { Atlântico Leste, } \\
\text { Atlântico Sudeste, } \\
\text { Paraná }\end{array}$ & $\begin{array}{l}\text { Bambuí-Caatinga, } \\
\text { Barreiras, } \\
\text { Bauru-Caiuá, } \\
\text { Guarani, Serra } \\
\text { Geral }\end{array}$ & $\begin{array}{l}\text { MG: norte e nordeste estão no } \\
\text { Semiárido, de grande escassez } \\
\text { hídrica: são os } 85 \text { municípios de } \\
\text { menor desenvolvimento do Esta- } \\
\text { do; desastre do Rio Doce (2015); } \\
\text { RJ: poluição de mananciais e au- } \\
\text { mento da pressão populacional na } \\
\text { RM com a criação do COMPERJ; } \\
\text { SP: poluição de rios, conflito entre } \\
\text { RMSP, interior e litoral e danos } \\
\text { ambientais; pressão agroindustrial } \\
\text { e populacional na macrometrópole }\end{array}$ \\
\hline Sul & $\begin{array}{l}\text { Paraná, Uruguai, } \\
\text { Atlântico Sul }\end{array}$ & $\begin{array}{l}\text { Bauru-Caiuá, } \\
\text { Guarani, Serra } \\
\text { Geral }\end{array}$ & $\begin{array}{l}\text { RS: no noroeste, estiagens e uso } \\
\text { intenso na irrigação comprometem } \\
\text { mananciais urbanos; RM de Porto } \\
\text { Alegre tem alta demanda em usos } \\
\text { setoriais e as poluições industrial e } \\
\text { doméstica comprometem a quali- } \\
\text { dade da água }\end{array}$ \\
\hline $\begin{array}{l}\text { Centro- } \\
\text { Oeste }\end{array}$ & $\begin{array}{l}\text { Amazônica, } \\
\text { Tocantins-Araguaia, } \\
\text { Paraná, Paraguai }\end{array}$ & $\begin{array}{l}\text { Bambuí, Bauru- } \\
\text { Caiuá, Fraturado } \\
\text { Centro-Sul, } \\
\text { Guarani, Parecis, } \\
\text { Serra Geral }\end{array}$ & $\begin{array}{l}\text { DF: próximo a nascentes, tem bai- } \\
\text { xa disponibilidade hídrica, mas } \\
\text { alta densidade demográfica, que } \\
\text { eleva a pressão por recurso hídrico; } \\
\text { MT: a inédita municipalização dos } \\
\text { serviços em todo o Estado, com } \\
\text { maioria de pequenos municípios, } \\
\text { criou obstáculos institucionais à } \\
\text { operação dos sistemas de abasteci- } \\
\text { mento de água }\end{array}$ \\
\hline
\end{tabular}

Fontes: Elaboração do autor, baseado em ANA (2010a, 2010b), Abreu, Cavalcanti e Matta (2013), MPESP (2015). 
No Sudeste, também é possível instalar usinas de dessalinização em Arraial do Cabo, Cabo Frio (RJ), aproveitando-se os potenciais eólico e solar para fazer o mesmo e enviar água e eletricidade à RM do Rio de Janeiro, resolvendo dois problemas. Em São Paulo, além do conflito da RMSP com o interior ${ }^{1}$ (Cantareira), a Sabesp criou outro com o litoral norte do Estado com a transposição do rio Itapanhaú para o Alto Tietê (UOL 2016); o Ministério Público do Estado de São Paulo (MPESP) pediu novas informações e novo parecer da Cetesb sobre o EIA-RIMA por haver, no projeto, riscos ao ambiente e à biodiversidade (MPESP 2015).

No norte e nordeste de Minas Gerais (Semiárido) há escassez hídrica superficial em 85 municípios das bacias dos rios Jequitinhonha, Pardo, Mucuri e afluentes do médio São Francisco, que possuem os menores indices de desenvolvimento econômico do Estado (ANA 2010b, 66). E, desde o fim de 2015, uma mineradora matou várias pessoas, destruiu a bacia do Rio Doce em Minas Gerais e Espírito Santo e as ecologias fluvial, litorânea e oceânica. Para que isso não se repita, exige-se rígida fiscalização obedecendo aos princípios da prevenção e da precaução do Direito do Ambiente, considerando o princípio maior da Ecologia Profunda, no qual a vida humana vale mais que toda a riqueza mundial (Milaré 1998, 60-62; 2001, 87).

Para alcançar a segurança hídrica, o Atlas investirá $\mathrm{R} \$ 70,0$ bilhões em água e esgotos; destes, $\mathrm{R} \$ 47,8$ bilhões em esgotos, mas só $\mathrm{R} \$$ 7,0 bilhões ao tratamento; os demais $\mathrm{R} \$ 40,8$ bilhões irão para redes coletoras que já deveriam existir, porque os investimentos em esgotos não acompanham os destinados à água potável (ANA 2010a, 60). As prioridades do Atlas são: proteger e recuperar mananciais sob grande pressão populacional, como dos rios Guaíba (Porto Alegre), Guandu (Rio de Janeiro) e Meia Ponte (Goiânia); ampliar o tratamento dos esgotos para proteger as captações dos reservatórios que abastecem a $\mathrm{RM}$ de Campinas, as represas Guarapiranga e Billings (RMSP) e os açudes do Nordeste (ANA 2010b, 60). O Atlas propõe a criação de um Comitê Gestor Interministerial, com suporte técnico da ANA, articulado com Estados e Municípios, para garantir água aos centros urbanos do País (ANA 2010a, 68). A seguir descrevemos tecnologias que poupam água e aumentam a segurança hídrica.

\section{Tecnologias que poupam recurso hídrico}

"Conservar recursos hídricos requer: estratégias e tecnologias para obter mais água, diminuir desperdícios e consumo excessivo, técnicas de reuso, conservação e proteção de mananciais superficiais e subterrâneos em níveis local, regional e global” (Tundisi 2005, 203). 
Em 2015, o sistema Cantareira precisava de 30 milhões de árvores, ao custo de $\mathrm{R} \$ 195$ milhões, para reflorestar 34 mil ha de matas ciliares de uma desmatada de 352 mil ha (Sant'Anna 2015), revelando, na escala local-regional, que não há "jeitinho" aos desrespeitos às leis da natureza e à legislação ambiental; sem chuvas, cobertura vegetal nem fiscalização, e com consumo excessivo, o Cantareira secou, mas basta determinação para enfrentar os problemas.

A Comissão Senado do Futuro estudou legislação e políticas ambientais de Áreas de Preservação Permanente (APPs) urbanas que, quando recuperadas, cumprirão funções ecológicas de proteção a solos e a corpos d'água, refúgio de fauna, corredores ecológicos e atenuação do clima urbano, melhorando a qualidade ambiental. Deve-se ajustar políticas ambientais urbanas compartilhadas entre municípios e Estados para recuperar, manter, monitorar e fiscalizar as APPs urbanas. A Universidade de Brasília levantou o estado de conservação de APPs nas 700 cidades de maiores pressões de expansão urbana, para subsidiar ações legislativas e decisórias de recuperação, conservação e monitoramento para planejar e ordenar a ocupação e políticas públicas futuras (Brasil 2015, 39-44).

Para poupar recurso hídrico, Fábio da Silva e Alexei Patrocínio atuaram em usinas sucroalcooleiras de São Paulo e economizaram 18\% de água com limpeza a seco da cana e refrigeração por torre de resfriamento (Silveira 2015, 68), reduzindo a pressão sobre outros usos. Inventada em Israel, a irrigação por gotejamento supre água e fertilizantes (fertirrigação) direto às raízes, com eficiência de 95\% no uso de água (Sitton 2000, 11 ); por ser simples e fácil de usar, deve ser incentivada no semiárido (G1 2013) e em áreas de intenso uso de recurso hídrico, como em São Paulo.

O sensor de solo, criado por Adonai Carvalho para frutas e hortaliças, poupa 50\% de água e fertilizantes (Bretanha 2015); Sonia Zanetti desenvolveu um sensor semicondutor e um sistema que medem a umidade do solo e poupam $30 \%$ de recurso hídrico, pois monitoram temperatura e umidade da terra e o produtor acessa dados de clima, solo e plantio em smartphones (Fapesp 2015, 68). Em Santa Rita do Sapucaí (MG), quatro engenheiros criaram o SMPIn (Sistema de Monitoramento de Plantações Inteligentes) que automatiza a irrigação, poupa 40\% de água e 28\% de energia, avalia o microclima e reduz os custos do produtor (Fapesp 2015, 68-69).

As técnicas de reuso da água são importantes na agricultura e o tratamento de esgotos é grande oportunidade para poupar água de mananciais. A equipe do Prof. Edson Matsura tratou os esgotos da Feagri/Unicamp, aplicou-os em área de 0,5 ha com cana-de-açúcar sob fertirrigação, poupou $50 \%$ dos fertilizantes nitrogênio e fósforo na primeira colheita e $100 \%$ na segunda, com produtividade de mais de 200 ton/ha, o dobro de áreas sem 
irrigação. Para Adolfo Melfi, o uso de esgotos domésticos tratados no cultivo de cana-de-açúcar aumentou a produtividade em 60\%, mas é preciso solucionar os problemas de saúde pública e legislação para disciplinar o reuso de esgotos tratados e atender aos parâmetros de saúde (Silveira 2015, 66-8).

Quanto ao abastecimento urbano, mais de $95 \%$ da água potável distribuída não é utilizada para beber, sendo desperdício inaceitável. As instalações prediais deveriam ter dois sistemas de abastecimento de água: um potável e outro não potável (Scaloppi 2013), bastando criar a legislação para que o mercado se adéque a ela. As medidas descritas acima, quando universalizadas, elevarão a segurança hídrica interna do país, que também busca superar desafios futuros, tais como escassez de água e energia, dentre outros, junto à comunidade das nações. Portanto, a próxima seção trata da segurança hídrica na escala geográfica internacional, a dimensão externa da Geopolítica do Meio Ambiente.

\section{EIXO HORIZONTAL: A GEOPOLÍTICA DO MEIO AMBIENTE}

Fundamentados em Marques e Medeiros Filho (2014), chamamos a escala internacional da segurança ambiental de Geopolítica do Meio Ambiente e a comentaremos nas escalas regional e global.

\section{América do Sul: o entorno estratégico}

As bacias Amazônia e Platina e o Aquífero Guarani compõem a seção. Vimos que internamente a década de 1980 foi ambientalmente decisiva, mas externamente o Brasil atua desde a década de 1960 na bacia Platina.

\section{O Centro-sul do Continente}

Em 1969 o Tratado da Bacia do Prata (TBP) foi assinado em Buenos Aires (Argentina), cujos artigos $1^{\circ} \mathrm{b}, 5^{\circ}$ e $6^{\circ}$ possibilitaram acordos entre nações ligados à navegação e à geração de hidreletricidade (TBP 1970), dando base legal à construção da Usina Hidrelétrica de Itaipu por Brasil e Paraguai.

As bacias dos rios Paraguai, Uruguai e Paraná formam a bacia do Rio da Prata e o Brasil ocupa metade da bacia, onde as chuvas variam de 1800 $\mathrm{mm}$ no leste a $200 \mathrm{~mm}$ no oeste. Os aquíferos principais são o Guarani e o Yrenda-Toba-Tarijeño (sob o semiárido) e, devido ao clima único no mundo propiciado pela Amazônia, há florestas, chuvas e recurso hídrico, solos e minérios que concentram 70\% do PIB e mais de 100 milhões de habitantes entre Buenos Aires, Brasília, Assunção, Montevidéu e Sucre (MMA 2009, 29; CIC 2011, 5; Nobre 2014, 4). 
As nascentes dos três rios da bacia do Rio da Prata estão no Brasil (Figura 3). Nas cabeceiras do rio Paraguai, a conservação engloba a proteção ao Pantanal, Patrimônio Nacional e Reserva da Biosfera. Mas, desde a década de 1970, a expansão da bovinocultura e da sojicultura no planalto provoca desmatamento, erosão e assoreia os rios do Pantanal (ANA 2016a), comprometendo a navegação e o equilíbrio sazonal da região, pois intensifica secas e cheias. O Brasil deve melhorar o transporte fluvial e a oferta de água em quantidade e qualidade para si e aos parceiros do TBP a jusante da bacia.

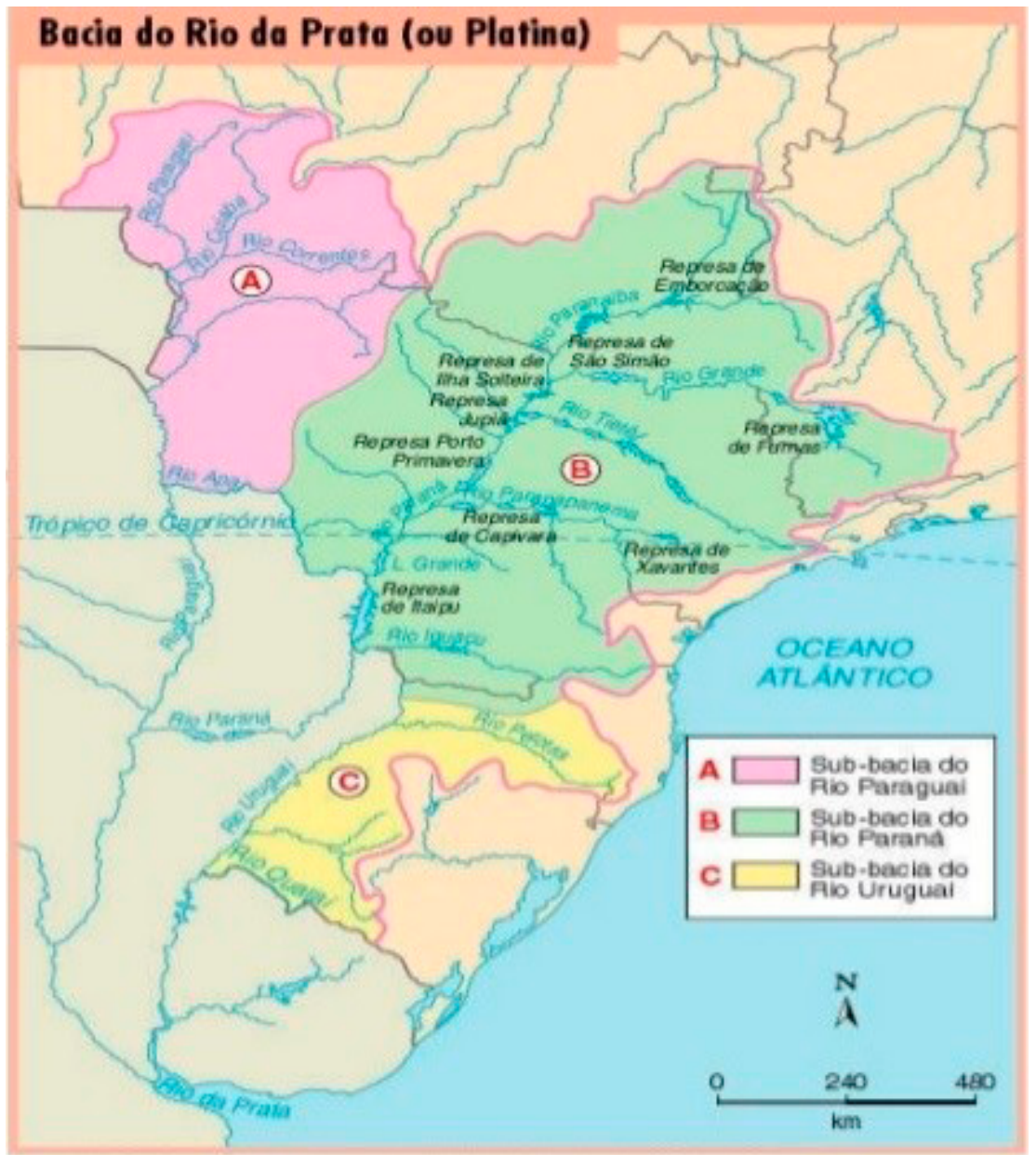

Figura 3. Área da Bacia do rio da Prata no Brasileira Fonte: IBGE (2000, 61). 
A bacia do rio Paraná é a mais povoada e desenvolvida economicamente, mas a de piores impactos nos recursos hídricos; em 2010 havia 61,3 milhões de pessoas no Brasil (93\% em cidades); por isso, é a região de maior demanda por recurso hídrico no país, equivalente a $31 \%$ da demanda nacional, com $42 \%$ destinados à irrigação, $27 \%$ à indústria e o restante a domicílios e à hidreletricidade (ANA 2016a). Grandes cidades da megalópole, como São Paulo, Campinas e Piracicaba estão na área, que possui conflitos de uso entre a RMSP e as bacias do consórcio PCJ no interior, devido à concorrência entre ambas as regiões por usos doméstico, agrícola, industrial e geração de hidreletricidade (ANA 2010b).

$\mathrm{Na}$ bacia do rio Uruguai destacam-se a agroindústria e o potencial hidrelétrico, mas em 2010 a maior parte da região abastecia a população abaixo da média nacional (91\%); apenas $33 \%$ da população possuía rede de esgotos e somente $10 \%$ eram tratados, abaixo da média nacional, de $30 \%$; grande parte da região está muito desmatada (ANA 2016a), o que compromete a qualidade da água destinada às nações vizinhas, a jusante do Brasil.

A bacia do Prata é rica em águas subterrâneas, que coincidem com o Aquífero Guarani (1.200.000 km²), um dos maiores reservatórios subterrâneos de água doce do mundo, que ocupa 9,8\% do território no Brasil, 8,1\% na Argentina, $17,6 \%$ no Paraguai e 33,2\% no Uruguai; suas profundidades variam de $50 \mathrm{~m}$ a $1.800 \mathrm{~m}$, com $45.000 \mathrm{~km}_{3}$ armazenados e volume explorável estimado em $166 \mathrm{~km}_{3} /$ ano ou $5.000 \mathrm{~m}_{3} / \mathrm{s}$ (MMA 2009, 30; CIC 2016).

Quanto às pesquisas para conservar o Aquífero Guarani, a busca "acuífero guarani”, na página de dados dos projetos do CIC, retornou 2418 trabalhos científicos em diversos campos da ciência, sobre as condições socioeconômicas e socioambientais da população; mas, devido à importância do assunto, a segurança hídrica da área do TBP e do Aquífero Guarani será aprofundada em artigo futuro. Vejamos agora o norte da América do Sul: a Amazônia.

\section{O Norte da América do Sul}

Depois do TBP, o Brasil voltou-se ao norte do continente e propôs o TCA, assinado pelas oito nações amazônicas em 1978; comenta-se alguns aspectos para responder à questão sobre como utilizá-lo para conservar a Amazônia, da qual o Brasil detém grande parte da floresta, mas não das nascentes dos rios principais; ressalte-se a importância estratégica da Amazônia em todas as escalas geográficas; há um esforço internacional para conservá-la, não só devido às secas de 2005 e 2010, também porque influi diretamente na sobrevivência do Centro-Sul do Brasil e do continente e tem um dos maiores aquíferos do mundo, o SAGA (Fearnside 2005, 2006; Abreu Cavalcanti; Matta 2013; Nobre 2014). 
Em 2001 a parte não amazônica do país sofreu racionamentos de eletricidade devido à falta de água nos reservatórios das usinas hidrelétricas que enchem em poucas semanas entre dezembro e janeiro, no pico da estação chuvosa na região Centro-sul, período do ano cujas chuvas provindas da Amazônia têm a máxima contribuição. As cidades principais do Brasil já estão no limite de abastecimento e qualquer redução significativa de transporte de vapor de água da Amazônia traria sérias consequências sociais (Fearnside 2006, 397). "O fornecimento de vapor de água [da Amazônia] é particularmente importante para evitar o prolongamento da estação seca em São Paulo, a região agrícola mais produtiva do Brasil" (Fearnside 2005, 117 , grifos nossos).

Artaxo descobriu que as plantas emitem gases que se convertem em aerossóis que formam as nuvens e controlam o clima, gerando chuvas; do total que chega ao Sudeste, 30\% vem do Sul, 30\% do Oceano Atlântico e $40 \%$ da Amazônia. Como o Brasil desmatou 20\% de sua Amazônia e 40\% do vapor de água do Sudeste vem de lá, houve $20 \%$ de perdas totais de chuva e de $8 \%$ no Sudeste (Artaxo apud Pivetta 2016, 29-30).

Nobre (2014) revelou cinco segredos sobre a importância da Amazônia para o Centro-sul do continente: 10 . Ela mantém os ventos úmidos e leva chuvas ao distante interior do continente, porque as árvores bombeiam muita água do solo para a atmosfera; 20 . Formam-se chuvas abundantes em região de ar limpo porque as árvores emitem aerossóis que condensam o vapor d'água; 3o. Sobreviveu a cataclismos climáticos porque sustenta um ciclo hidrológico benéfico, mesmo em condições externas desfavoráveis (teoria da bomba biótica/SAGA); 4o. O sul da América do Sul, a leste dos Andes, não é um deserto, como áreas de mesma latitude neste e em outros continentes, porque ela mantém o ar úmido para si mesma e exporta rios aéreos de vapor, que levam água às distantes chuvas de verão, formando um quadrilátero de prosperidade, responsável por 70\% do PIB do continente, entre Cuiabá (norte), São Paulo (leste), Buenos Aires (sul), e os Andes (oeste); 5o. Na Amazônia e nos oceanos próximos não há eventos climáticos extremos porque a condensação uniforme sobre a floresta impede a concentração de energia dos ventos em vórtices destrutivos e a remoção da umidade atmosférica de cima do oceano extingue as tempestades nas regiões oceânicas próximas às grandes florestas (Nobre, 2014: 4-5; 18). Supomos que Mata Atlântica e Cerrado, quando recobriam o país, juntos cumpriam papéis semelhantes e também evitavam eventos extremos no interior do continente.

Mas é preciso agir rápido para manter esse patrimônio comum sul-americano. A Figura 4 mostra que Amazonas (54\%), Rondônia (41\%) e Mato Grosso (40\%) foram os campeões do desmatamento, por expansão do agronegócio. Os grandes desmatamentos voltaram devido a falhas na fiscali- 
zação dos órgãos ambientais oficiais e à desarticulação entre o governo federal e os estaduais, ministérios e perda do tratamento estratégico do tema desde 2011 , quando a legislação transferiu muitas responsabilidades de fiscalização e supressão de vegetação aos órgãos estaduais; os dados revelam o despreparo destes órgãos para cumprir tais funções (ISA, 2015).

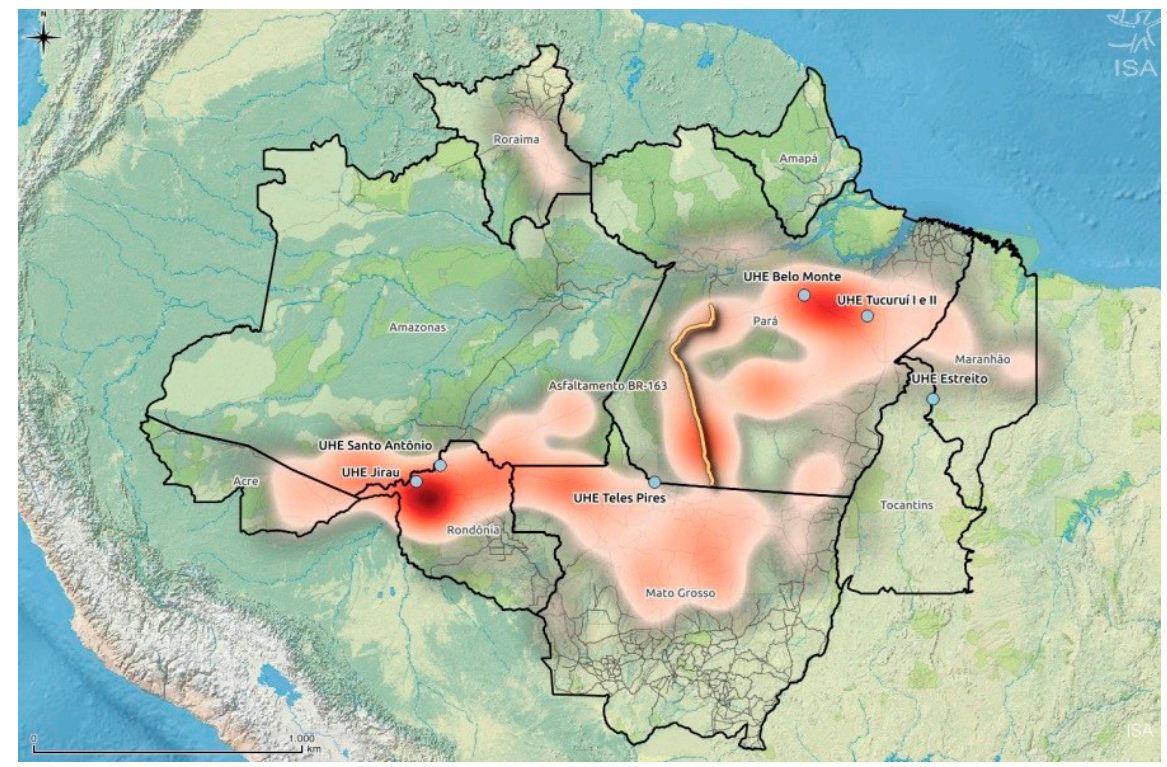

Figura 4-Desmatamento na Amazônia Brasileira.

Fonte: ISA (2015).

Mas, como parar o desmatamento, reflorestar e desenvolver a região? No Brasil, a resposta inclui legislação e fiscalização ambiental, zoneamento agroecológico, instrumentos jurídicos e econômicos, atores públicos e privados, ONGs e sociedade civil; externamente, envolve a cooperação entre nações da OTCA, que detêm as cabeceiras dos rios amazônicos, dos quais o Brasil depende e é responsável direta e constitucionalmente pela estabilidade do centro-sul do continente, pois abriga grande parte da Amazônia, várias nascentes da bacia platina (TBP) e trechos importantes do aquífero Guarani.

Embora o termo ainda não existisse, o TCA tem compromisso com o desenvolvimento sustentável: “ $[\ldots]$ para lograr um desenvolvimento integral dos respectivos territórios da Amazônia é necessário manter o 
equilíbrio entre o crescimento econômico e a preservação do meio ambiente [...]”. Seu teor visa ao desenvolvimento conjunto dos territórios amazônicos dos signatários $\left(\operatorname{art.~} 1^{\circ}\right)$, cooperação em Saúde $\left(\operatorname{art.~} 8^{\circ}\right)$ e Ciência, Tecnologia, Educação e desenvolvimento (art. $\left.9^{\circ}\right)$, proteção à sociedade, aos indígenas e ao meio ambiente (art. 11 e 14), uso racional de recursos hídricos $\left(\operatorname{art} 5^{\circ}\right)$ e navegação $\left(\operatorname{art.} 6^{\circ}\right)$ (Brasil 1980).

A AECA tem oito temas, e destacamos o tema $A$. Conservação, proteção $e$ aproveitamento sustentável dos recursos naturais renováveis, e seu subtema $A 1$. Florestas, para monitorar a cobertura e controle florestal, manejar a floresta inclusivamente e incentivar o reflorestamento; o subtema A2. Recursos hídricos, trata da quantidade e qualidade das águas para a saúde da população e destacam-se: facilitar acesso à água de qualidade; estimular a participação das populações vulneráveis em debates sobre recurso hídrico; controlar atividades de mineração que contaminam as águas e implementar uma gestão integral e sustentável dos recursos hídricos da Amazônia (OTCA 2011, 24-26).

No tema E: Infraestrutura e transporte, o fluvial é importante na Amazônia; mantê-lo implica preservar a integridade dos rios, sendo necessário recuperar e conservar a floresta, como previsto no citado artigo $6^{\circ}$ do TCA (OTCA 2011, 46). O tema H, temas emergentes, possui ações para a saúde da população, segurança alimentar e mudanças climáticas, manutenção e recuperação da floresta amazônica e de bacias degradadas (OTCA 2011, 52-53). Como a Amazônia influencia diretamente no clima sul-americano e, como importante sequestradora de carbono, também atua indiretamente no clima mundial, inclui-se na Geopolítica mundial, por envolver a mitigação das mudanças climáticas, razão do próximo item.

\section{A Amazônia na geopolítica mundial}

A Amazônia mantém o clima amigo do centro-sul da América do Sul (Nobre 2014), tem sido fertilizada pela poeira do Saara africano (Koren et al. 2006, 1), tem a maior biodiversidade do planeta (Museu Paraense 2012) e sequestra grandes quantidades de carbono. Uma área em regeneração absorveu 34,9 Tg C/ano em 13.717 kme entre 1988 e 1994 (Sawyer 2009, 152), portanto, seria possível reabsorver $1,7 \mathrm{Tg} \mathrm{C} /$ ano caso toda a área desmatada no Brasil fosse reflorestada; isso é mais que as emissões de 2010 contabilizadas pelo SIRENE, de 1,3 $\mathrm{Tg} \mathrm{CO}_{2}$ eq (Brasil 2010), evidenciando o imenso potencial de sequestro de carbono da Amazônia e sua importância para o clima mundial.

Das emissões brasileiras de gases de efeito estufa (gee) em 2010, 32\% vieram da agropecuária, $29 \%$ da geração de energia com queima de combustíveis, $28 \%$ de uso da terra, mudança de seu uso e florestas, predomi- 
nando desmatamentos da Amazônia e outros biomas, 7\% de processos industriais e $4 \%$ do tratamento de resíduos (Brasil 2010). Contabilizando-se todos os gee $\left(\mathrm{CO}_{2}, \mathrm{CH}_{4}, \mathrm{~N}_{2} \mathrm{O}\right.$, clorados e $\left.\mathrm{SF}_{6}\right)$, em 1990 as emissões foram de 1,35 $\mathrm{Tg} \mathrm{CO}_{2}$ eq/ano; o valor subiu a $2 \mathrm{Tg}$ em 2000 e a 2,2 $\mathrm{Tg}$ em 2005. Entre 1990 e 2005 o PIB subiu $47 \%$ mas as emissões subiram $68 \%$ em energia, $70 \%$ em desmatamento e $77 \%$ no tratamento de resíduos; somente na agricultura (42\%) e em processos industriais (39\%) as emissões cresceram menos que o PIB (MCT 2005). Em 2010 o total emitido foi de $1,2 \mathrm{Tg} \mathrm{CO} 2$ eq/ano, uma queda de $38,7 \%$ sobre 2005 , mas as projeções de emissões para 2020 são de 3,2 Tg; infelizmente, a maior parte virá de mudança do uso da terra e florestas, energia e agropecuária (MCT 2013, 11); mas o Decreto $\mathrm{n}^{\circ} 7.390$ busca reduzir isso para $2 \mathrm{Tg} \mathrm{CO}_{2} \mathrm{eq} / \mathrm{ano}(\mathrm{MCT}$ 2014, 33).

A AECA da OTCA coaduna-se à COP 21 da Conferência da Mudança do Clima (CMC), nos temas emergentes Mudança Climática e Energia; em Mudanças Climáticas há avaliação econômica da floresta e de seus bens e serviços; projetos de mecanismos de desenvolvimento limpo e programas de mitigação das mudanças climáticas; em Energia destacam-se: intercâmbio tecnológico entre os membros para gerar energia limpa e sem agressão ao ambiente; pesquisas sobre novas e adequadas formas de energia para a região (OTCA 2011, 52 e 54).

Em 2015, houve em Paris um acordo para conter o aumento da temperatura global em $1,5^{\circ} \mathrm{C}$, com revisão das metas voluntárias das Contribuições Nacionalmente Determinadas (INDCs, em inglês) a cada cinco anos e, a partir de 2020, os países desenvolvidos destinarão US $\$ 100$ bilhões anuais para ajudar os países em desenvolvimento a reduzir emissões (Marques 2016, 32). O Brasil comprometeu-se a emitir 37\% menos em 2025 e 43\% menos em 2030 do que em 2005, mas, para isso, deve aumentar em 18\% a participação de bioenergia sustentável na matriz energética, elevar para $45 \%$ a participação de energias renováveis, zerar desmatamentos, re $\square$ orestar 12 milhões de hectares, melhorar a produtividade e a eficiência de indústrias, automóveis e de geradores elétricos (Marques 2016, 33).

Na Conferência do clima, o Brasil divergiu de outros Brics ao participar da Coalizão de Alta Ambição, junto a EUA, UE e mais de 100 países, liderada pelas Ilhas Marshall e deixou de ser porta-voz dos países pobres, contrariando o passado para conseguir um acordo melhor, fato que concluiu a mudança de paradigma ambiental do país. O país deve rever o plano de exportar petróleo para se desenvolver, pois contraria a tendência mundial de descarbonização, atrair investimentos para reflorestar, sequestrar carbono e gerar energias eólica e solar. Para descarbonizar a matriz energética e ter desempenho de país desenvolvido, o Brasil deve modernizar indústrias e 
tecnologias para economizar insumos e energia, iniciando pela agricultura, cujas vantagens comparativas adquiridas com o etanol de cana-de-açúcar podem se repetir em outros setores para cumprir os compromissos apresentados na COP 21, apoiados pela Secretaria de Meio Ambiente de São Paulo, via Universidades Estaduais e FAPESP (Goldemberg 2015a, b).

Mas a energia fóssil continua importante a médio prazo, pois responde por $20 \%$ do PIB mundial e recebe US $\$ 700$ bilhões anuais de investimentos (Câmara apud Marques 2016, 34-35). O relatório Energy Outlook da $\mathrm{BNEF}$ calcula investimento global de US $\$ 7,8$ trilhões em fontes eólicas, solar e biomassa até 2040, quando as fontes renováveis serão responsáveis por $70 \%$ da energia gerada na Europa e 44\% nos EUA, também devido à queda nos custos de geração das energias solar e eólica (Tomaz Jr. 2016, 5).

Para a senadora Kátia Abreu, relatora da ratificação do Acordo do Clima na Comissão de Relações Exteriores e Defesa Nacional (CRE), o país cumprirá as metas de redução de emissões e admitiu a importância geopolítica da proteção ao meio ambiente: “[ ...] Não é mais uma agenda ambiental. Essas conferências e esses compromissos são uma agenda geopolíti$c a$. Ela deixa de ser uma agenda ambientalista”. O Presidente da República ressaltou que o clima é uma questão de Estado para o Brasil, resultado da Rio 92 e da Rio+20 (2012), que mostraram ao mundo a preocupação do Brasil com o meio ambiente. O Ministro do Ambiente destacou que a mudança do clima é o maior desafio deste século e oportunidade para reorientar o projeto de desenvolvimento econômico sustentável do Brasil (Sputnik 2016a, c).

China e EUA emitem mais de 50\% do total, os EUA prometem reduzir as emissões em $27 \%$ sobre 2005 e a China a reduzir o uso de carvão até 2030 para que as emissões cresçam menos que a economia. A União Europeia emite 14\% dos gee e reduz isso desde 1992 empregando melhores tecnologias e energias renováveis (Artaxo apud Pivetta 2016, 26; Goldemberg 2015a, b). Em 2016 o Acordo de Paris sobre Mudança Climática foi ratificado por Brasil, China, EUA, Rússia e outros, totalizando 55 Estados que emitem 55\% dos gee, e entrou em vigor em quatro de novembro (G1 2016).

O professor David Zee (UERJ) salientou que o Brasil se destaca na contribuição para a redução signi $\square$ cativa da emissão dos gee e reforçou que o clima é uma questão política porque só a partir da conscientização e da de $\square$ nição política de cada país é que haverá um esforço conjunto efetivo porque a política pressupõe a concordância da maioria (Sputnik 2016b). E, por ter sediado duas conferências mundiais de meio ambiente, o Brasil tem representatividade e responsabilidade como um país símbolo, por possuir a Floresta Amazônica, enormes recursos naturais e papel de liderança junto a outros países, influenciando-os para conter os gee (Sputnik 2016b), evidenciando o Brasil como player mundial da geopolítica do meio ambiente. 


\section{CONSIDERAÇÕES FINAIS}

No eixo vertical da segurança (plano interno da segurança hídrica), poupar recurso hídrico no campo inclui tecnologias de gerenciamento do uso da água e ações políticas, como reflorestamentos e fiscalização rigorosa a outorgas de uso e a desmatamentos. Ao acelerar a implantação das energias renováveis, como eólica e solar, o recurso hídrico será poupado e os conflitos de uso podem diminuir, ampliando-se a segurança hídrica. Dirimir tais conflitos nas cidades inclui a gestão democrática, conter vazamentos nas redes de distribuição e desperdícios em domicílios e indústrias e universalizar a coleta e o tratamento de esgotos.

Deve-se: incentivar a educação ambiental para influenciar padrões de consumo de água, carne, combustíveis e energia; recuperar e conservar APPs e implantar leis de captação e reuso da água para dirimir conflitos, melhorando o abastecimento nas regiões metropolitanas e no semiárido; fortalecer agências de fiscalização e regulação para a proteção de mananciais, o que cumprirá o direito humano de acesso à água de qualidade a todo o povo, tornando-se uma das bases do desenvolvimento socioambiental sustentável e igualitário.

No eixo horizontal da segurança (Geopolítica do Meio Ambiente, no plano externo da segurança hídrica), a gestão conjunta da AECA para conservar a Amazônia contribuirá para manter e ampliar recursos hídricos compartilhados, essenciais ao desenvolvimento sustentável do país e dos vizinhos, no entorno estratégico. Já o Brasil, como integrante das bacias Amazônica e Platina, tem dupla responsabilidade: primeira, ocupa a Amazônia, rica em recurso hídrico superficiais e subterrâneos (SAGA), mas depende dos vizinhos onde nascem os rios da Amazônia brasileira, deve mantê-la e reflorestá-la por vários motivos, inclusive a influência direta no clima do Centro-Sul do continente, seu coração geoeconômico (heartland); segunda, o Brasil detém nascentes de rios, grande parte da bacia Platina e do aquífero Guarani, devendo zelar pela qualidade destes recursos hídricos compartilhados. Tais ações minimizarão riscos de desastres ambientais e crises hídricas futuras, atenuando impactos na qualidade de vida, na economia e na posição geopolítica do país e de nossos vizinhos.

Quanto ao clima global, a Amazônia tem importância geopolítica mundial devido à imensa capacidade de sequestrar carbono e, como o Brasil assumiu na Conferência de Paris (2015) propostas ousadas de corte de emissões, sua conservação é fundamental para que o país caminhe rapidamente à economia de energias limpas e poupadoras de recurso hídrico, numa complexa ação político-tecnológica. Além disso, a ex-ministra Katia Abreu admitiu a existência da Geopolítica do Meio Ambiente quando afir- 
mou que os compromissos assumidos pelo país na área ambiental são uma agenda geopolítica.

Cumprir os objetivos da Conferência de Paris não será fácil para o Brasil porque, antes de reflorestar 12 milhões de hectares na Amazônia, é preciso zerar os desmatamentos lá e em todo o país, para depois reflorestá-lo, e também na Amazônia, para manter o continente habitável. Como somente $11 \%$ das emissões originaram-se nas cidades em 2010, há um imenso trabalho no campo brasileiro para deter as emissões, como o Decreto $\mathrm{n}^{\circ} 7.390$ demonstra, mas a descoberta da terra preta de indio, relatada por Sawyer (2009), pode ser uma alter nativa para produzir alimentos e, ao mesmo tempo, sequestrar carbono.

Portanto, desde 1960 o Brasil atua em Geopolítica e em Direito do Meio Ambiente, ao cooperar com os povos vizinhos para manter as seguranças nacional e regional, que são interdependentes. $\mathrm{O}$ país pode mostrar ao mundo ações para manter e ampliar a segurança hídrica e melhorar a vida do povo, buscando o desenvolvimento sustentável; fazendo assim, o Brasil e seus vizinhos amazônicos e platinos compartilhariam uma gestão multipolar pacífica do recurso hídrico e inibiriam, como alertado por Vianna (2005, 360), as pretensões invasoras em nome da "proteção à Amazônia".

\section{REFERÊNCIAS}

Abreu, F. A. M; Cavalcante, I. N.; Matta, M. A. S. 2013. O sistema aquífero grande Amazônia - SAGA. III Congresso Internacional de Meio Ambiente Subterrâneo, São Paulo, 1-3, out. 2013. Disponível em: <https://aguassubterraneas.abas.org/asubterraneas/article/viewFile/27523/17790>. Acesso: 22 dez. 2016.

ANA. 2010a. Atlas Brasil: abastecimento urbano de água. Panorama Nacional. Brasília: ANA. Disponível em: <http://atlas.ana.gov.br/Atlas/downloads/ atlas/Resumo\%20Executivo/Atlas\%20Brasil\%20-\%20Volume\%201\%20-\%20 Panorama\%20Nacional.pdf> . Acesso em: 16 mai. 2016.

2010b. Atlas Brasil: abastecimento urbano de água. Resultados por Estado. Brasília: ANA. Disponível em: <http://atlas.ana.gov.br/Atlas/downloads/ atlas/Resumo\%20Executivo/Atlas\%20Brasil\%20-\%20Volume\%202\%20-\%20

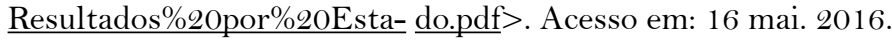

2014. Termo de Referência: Plano Nacional de Segurança Hídrica. Disponível em: <http://interaguas.ana.gov.br/Lists/Licitacoes_Docs/Attachments/32/ TDR_PNSH_Prelimi- nar.pdf> Acesso em: 15 mai. 2016.

2016a. Bacias Hidrográficas. Disponível em: <http://www2.ana.gov.br/ Paginas/portais/bacias/default.aspx>. Acesso em: 27 jul. 2016. 
2016b. Renovação da Outorga do Sistema Cantareira. Disponível em: <http://www2.ana.gov.br/Paginas/servicos/outorgaefiscalizacao/renovacaocantareira.aspx>. Acesso: 26 jun. 2016.

Andrade, M. C. 1989. Geopolítica do Brasil. São Paulo: Ática.

Balmford, A. et al. 2002. Economic reasons for conserving wild nature. Science, 297, 950-953. Disponível em: $<$ http://science.sciencemag.org/content/297/5583/950>. Acesso em: 05 out. 2017.

Bassoi, L. J., Guazelli, M. R. 2004. Controle ambiental da água. In: Philippi Jr., A., Roméro, M. A., Bruna, G. C. (Ed.). Curso de Gestão Ambiental. Barueri: Manole, 53-99.

Becker, B. K. 1990. Amazônia. São Paulo: Ática.

2004. 7. Inclusion of the Amazon in the Geopolitcs of Water. Disponível em: <http://documentacion.ideam.gov.co/openbiblio/bvirtual/o20078/BOL59/ WaterfromtheAmazon/ 7Inclusionoftheamazon.pdf $>$. Acesso em: 6 Jan 2016.

Brasil. 1980. Tratado de Cooperação Amazônica. Brasília: Promulgado pelo Senado Federal no Decreto $n^{\circ}$ 85.050, de 18 de agosto de 1980. Disponível em: <http:// legis.senado.gov.br/legisla- cao/ListaPublicacoes.action?id=126133>. Acesso em: 12 jan. 2016 .

1997. Lei $n^{\circ}$ 9.433, 8 jan. 1997. Institui a Política Nacional de Recursos Hídricos. Disponível em: <https://www.planalto.gov.br/ccivil 03/LEIS/L9433. $\underline{\mathrm{htm}}>$. Acesso em: 24 jul. 2016.

. 2010. MCT. Sistema Nacional de Registro de Emissões (SIRENE). Disponível em: <https://www.youtube.com/watch?v=foh96n $1 \mathrm{gItE}>$. Acesso em: 12 out. 2016.

. 2014a. Governo lança Plano Nacional de Segurança Hídrica. Portal Brasil. 20 ago. 2014. Disponível em: <http://www.brasil.gov.br/meio-ambiente/2014/08/ governo-lanca-plano-nacional-de-seguranca-hidrica>. Acesso em: 13 mai. 2016.

2014b. Programa de Desenvolvimento do Setor Água - INTERÁGUAS. Disponível em: <http://interaguas.ana.gov.br/Paginas/Programa.aspx >. Acesso em: 13 mai. 2016.

. 2015. Relatório n. 20, Comissão Senado do Futuro. Disponível em: $<$ www 19.senado.gov.br/sdleg-getter/public/getDocument?docverid=84e44c6d. pdf $>$. Acesso em: 3 jun. 2016. 
2016. MRE. Organização do Tratado de Cooperação Amazônica (OTCA). Disponível em: $\leq$ http://www.itamaraty.gov.br/index.phpoption $=$ com content\&v iew $=$ article\&id $=691 \&$ catid $=146 \& I$ temid $=434 \&$ lang $=p t-B R>$. Acesso em: 12 jan. 2016.

Bretanha, B. 2015. Com sensor, irrigação usa metade da água. Caderno do Agronegócio, O Estado de São Paulo, 27 fev. 2015, p. 10.

CIC. 2016. Agua Subterrânea. Sistema acuífero Guaraní. Disponível em: <http:// www.cicpla- ta.org/?id=lc_aguasub\#sag > . Acesso em: 9 set. 2016.

Fapesp. 2015. Combate ao desperdício. Pesquisa, 234, 67-69.

Fearnside, P. M. 2005. Desmatamento na Amazônia brasileira. Megadiversidade, 1 (4), 113-123. Disponível em: <http://philip.inpa.gov.br/publ_livres/2005/ Desmatamento\%20historiaMegadiversidade.pdf $>$. Acesso em: 14 jan. 2016.

2006. Desmatamento na Amazônia. Acta Amazonica, 36 (3), 395-400. Disponível em: $\quad<$ http://philip.inpa.gov.br/publ_livres/2006/Acta\%20 Amaz-desmatamento.pdf $>$. Acesso em: 14 jan. 2016.

Foucault, M. 2005. Em defesa da sociedade. Tradução: Maria Galvão. São Paulo: Martins.

G1. 2013. Sistema de irrigação por gotejamento é adotado no Agreste de Alagoas. G1, Alagoas, 25 ago. 2013. Disponível em: <http://g1.globo.com/al/alagoas/ noticia/2013/08/sistema-de-irrigacao-por-gotejamento-e-adotado-no-agreste-de-alagoas.html>. Acesso em: 16 jan. 2016.

. 2016. Acordo do Clima de Paris entra oficialmente em vigor. Disponível em: <http://g1.globo.com/natureza/noticia/2016/11/acordo-do-clima-de-paris-entra-oficialmente-em-vigor-nesta-sexta-feira.html> Acesso: 15 nov. 2016.

GWP. 2000. Towards Water Security. Stockholm. Disponível em: <http://www. gwp.org/Global/ToolBox/References/Towards water security. A framework for ac- tion. Executive summary (GWP, 2000.pdf)>. Acesso em: 7 jan 2016.

Gómez, R. N. 2006. Les conséquences géopolitiques pour le Mexique de la politique états-unienne de homeland security. Hérodote, 123, 164 - 181. Disponível em: $\quad<$ https://www.cairn.info/load_pdf.php?download=1\&ID_ ARTICLE=HER_123_0164>. Acesso em: 20 dez. 2015.

Goldemberg, J. 2015a. Mudanças climáticas e inovação. O Estado de São Paulo, 19 de Outubro de 2015. Disponível em: $\leq$ http://opiniao.estadao.com.br/noticias/ geral,mudancas-clima-ticas-e-inovacao,10000000422 >. Acesso em: 15 jan. 2016. 
. 2015b. A conferência de Paris. O Estado de São Paulo, 21 de Dezembro de 2015. Disponível em: <http://opiniao.estadao.com.br/noticias/geral,a-conferencia-de-paris---uma-avaliacao,10000005385 >. Acesso em: 15 jan. 2016.

IBGE. 2000. Atlas Nacional do Brasil. 3. ed. Rio de Janeiro: IBGE.

ISA. 2015. Aumento do desmatamento fragiliza posição brasileira nas negociações climáticas internacionais. Disponível em: <https://www.socioambiental.org/pt-br/ noticias- socioambientais/aumento-do-desmatamento-fragiliza-posicao-brasileira-nas-negociacoes-climaticas-internacionais>. Acesso em: 1 jun. 2016.

Koren, I. et al. 2006. The Bodélé depression: a single spot in the Sahara that provides most of the mineral dust to the Amazon forest. Environ. Res. Lett. 1, 014005. Disponível em: <http://iopscience.iop.org/article/10.1088/1748-9326/1/1/014005/pdf > Acesso: O1 Out 2016. Magnoli, D. $O$ que é geopolítica.

Magnoli, D. 1994. O que é geopolítica. 4. ed. São Paulo: Brasiliense.

Marques, A. A., Medeiros Filho, O. 2014. Entre a 'Segurança Democrática' e a 'Defesa Integral': uma análise de duas doutrinas militares no canto noroeste do subcontinente Sul-Americano. In: Nasser, R. M., Moraes, R. F. (Org.). O Brasil e a Segurança no seu entorno estratégico. Brasília: IPEA, 43-58.

Marques, F. 2016. O começo da transição. Pesquisa, 239, 32-35.

Martins, M. A. F., Pianovski, D. 2013. A dimensão geopolítica da questão ambiental. Revista Eletrônica Pró-Docência/UEL, 5 (5), 25-43. Disponível em: <http://www.uel.br/revistas/prodocenciafope/pages/arquivos/Volume5/3.\%20 PIANOVSK\%20e\%20MARTINS.pdf>. Acesso em: 3 out. 2017.

Marshall, J. 2014. A gigante mineradora brasileira Vale”. Tensões mundiais, v. 10, n. 18-19. pp. 173-230. Disponível em: <http://www.tensoesmundiais.net/index. $\mathrm{php} / \mathrm{tm} /$ article/down- load/349/384>. Acesso em: 13 jan. 2016.

MCT. 2005. Inventário brasileiro das emissões de gases de efeito estufa. Disponível em: $<$ http://ecen.com/eee75/eee75p/inventario_brasil.htm>. Acesso em: 25 out. 2016.

2013. Estimativas anuais de emissões de gases de efeito estufa no Brasil. Disponível em: <http://www.mct.gov.br/upd_blob/0226/226591.pdf >. Acesso em: 15 out. 2016. 
2014. Estimativas anuais de emissões de gases de efeito estufa no Brasil. 2. ed. Disponível em: <http://www.mct.gov.br/upd_blob/0235/235580.pdf>. Acesso em: 15 out. 2016

Milaré, E. 1998. Princípios fundamentais do Direito do Ambiente. Revista dos Tribunais, 87 (756), 53-68.

2001. Direito do Ambiente. 2. ed. São Paulo: Revista dos Tribunais.

MMA. 2009. Processo formativo Brasil 2009. Campinas, São Paulo. 29 de setembro a 1 de outubro. Disponível em: <www.mma.gov.br/estruturas/srhu2008/ publicacao/157 publicacao03032011050756.pdf>. Acesso em: 27 jul. 2016.

MPESP. 2015. Gaema, Inquérito civil. Disponível em: <http://www.mpsp. $\mathrm{mp} . \mathrm{br} / \mathrm{portal} / \mathrm{page} / \mathrm{portal} / \mathrm{comunicacao} /$ Newsletter/imagens_newsletter/14.1090.0000008-2015.pdf $>$. Acesso em: 9 jul. 2016.

Museu Paraense. 2012. Biodiversidade da Amazônia. Disponível em: <http:// marte.museu-goeldi.br/marcioayres/index.php?option=com_content\&view=arti cle\&id=10\&Itemid=11>. Acesso em: 2 out. 2016.

Nobre, A. D. 2014. O futuro climático da Amazônia. São José dos Campos: ARA/ INPE/INPA. Disponível em: <www.ccst.inpe.br/wp-content/uploads/2014/11/ Futuro-Climatico-da-Amazonia.pdf $>$. Acesso em: 3 ago. 2016.

Norsal. 2016. A produção. Disponível em: <http://www.norsal.com.br/main. php?g_ct=producao $>$. Acesso: $1^{\circ}$ jul. 2016.

Odum, E. P. 2001. Introdução à Ecologia. Tradução de António Manuel de Azevedo Gomes. 6. ed. Lisboa: Fundação Calouste Gulbenkian.

OTCA. 2011. Agenda Estratégica de Cooperação Amazônica. Brasília: OTCA/ Programa Regional Amazônia. Disponível em: <http://www.otca.org.br/portal/ admin/_upload/apresentacao/AECA_prt.pdf>. Acesso em: 12 jan. 2016.

Pivetta, M. 2016. Física a serviço do planeta. Pesquisa, 239, 32-35, jan.

Ratzel, F. 1990. As leis do crescimento espacial dos Estados. In: Moraes, A. C. R. (Org.). Ratzel: Geografia. São Paulo: Ática, 175-192.

Ribeiro, S. L. 2006. Análise da Sustentabilidade na Bacia do rio Corumbataí (SP), (Tese, Unesp, Doutorado em Geociências). Rio Claro (SP), Unesp, 2006.

Sant'Anna, L. 2015. Sob ameaça, Cantareira precisa de 30 mi de árvores, ao custo de $\mathrm{R} \$ 195$ milhões. O Estado de São Paulo, 22 fev. 2015, A16. 
Sawyer, D. 2009. Fluxo de carbono na Amazônia e Cerrado. Sociedade e Estado, Brasília, 24 (1), 149-171, jan./abr. 2009. Disponível em: <http://www.scielo.br/ $\mathrm{pdf} / \mathrm{se} / \mathrm{v} 24 \mathrm{n} 1 / \mathrm{a} 07 \mathrm{v} 24 \mathrm{n} 1 . \mathrm{pdf}>$. Acesso em: 2 out. 2016.

Scaloppi, E. J. 2013. Reavaliando o consumo de água na cidade e no campo. Jornal Unesp, out. 2013, 4. Disponível em: <http://migre.me./g7nwB>. Acesso em: 16 jan. 2016.

Silveira, E. 2015. A contribuição do campo. Pesquisa, 229, 65-69.

Sitton, D. 2000. Development of limited water resources. Focus on Israel. Jerusalem: IIC.

Sputnik. 2016a. Brasil é primeiro país a ratificar no Senado Acordo de Paris sobre o clima. 11 ago. 2016. Disponível em: <http://sptnkne.ws/cyzV>. Acesso em: 12 out. 2016.

.2016b. David Zee sobre Acordo da COP21: 'O clima é uma questão política'. 12 set. 2016. Disponível em: <http://sptnkne.ws/cyzX>. Acesso em 12 out. 2016.

2016c. Ao ratificar Acordo de Paris, Temer destaca atuação do Brasil desde a Eco 92 e a Rio+20. 12 set. 2016. Disponível em: <http://sptnkne.ws/cyzY>. Acesso em: 12 out. 2016.

Tomaz Jr, R. 2016. Desenho do mundo. Caros amigos Especial. Superimperialismo: guerras urbanas, crises ambientais e domínio das corporações, XIX (82), 4-5.

Tratado da Bacia do Prata - TBP. 1970. Promulgado pelo Decreto $n^{\circ} 67.084,19$ ago. 1970. Publicado no DOU em 20 ago. 1970, p. 7. 371/72. Disponível em: <https:// www.dpc.mar.mil.br/sites/default/files/ssta/legislacao/hidrovia/trat_bcprata. pdf $>$. Acesso em: 12 ago. 2016.

Tundisi, J. G. 2005. Água no século XXI: enfrentando a escassez. 2. ed. São Carlos: RIMA-IIE.

UOL. 2016. Sabesp entregará em 2017 obra que permitirá o uso de até 2.500 litros de água por segundo. Disponível em: <http://www.uol/noticias/conteudo-publicitario/modelo-de-captacao-de-agua.htm\#sabesp-entregara-em-2017-obra-que-permitira-o-uso-de-ate-2500-litros-de-agua-por-segundo $>$ Acesso em: 7 jul. 2016.

Vesentini, J. W. 1987. A capital da Geopolítica. São Paulo: Ática.

Vianna, P. 2005. A água vai acabar? A importância dos conflitos pela água na formação do Brasil. In: Albuquerque, E. S. (Org.). Que país é esse? Pensando o Brasil Contemporâneo. São Paulo: Globo, 341-68. 
NOTAS

1. A renovação da Outorga do Sistema Cantareira, prevista para 2014, foi adiada para 2017 devido à seca de 2014-2015 (ANA 2016b). 


\section{RESUMO}

Como o recurso hídrico é um fundamento para a segurança e defesa do país, cremos que o Brasil deve executar sua gestão correta para garantir a segurança hídrica, condição essencial ao desenvolvimento nacional. Para isso, ampliamos o conceito de segurança de Marques e Medeiros Filho (2014), descrevendo ações de cunho tecnológico, político e geopolítico nos planos horizontal e vertical, para conservar a segurança hídrica do país ao gerenciar a intervenção nos ambientes amazônico e platino, uma responsabilidade comum dos Estados Sul-Americanos.

Palavras-chave: Geopolítica do Meio Ambiente; Recursos Hídricos; Segurança Hídrica.

\section{ABSTRACT}

As the water resource is a foundation for the country's security and defense, webelieve that Brazil must perform its correct management to guarantee water security, a condition essential to national development. Thus, we extended Marques and Medeiros Filho's concept of security (2014), describing technological, political and geopolitical actions in the horizontal and vertical axes, to preserve the country's water security by managing intervention in the Amazonian and Platinum environments, responsibility of many South American States.

Keywords: Geopolitics of the Environment; Water Resources; Water Security. 